International Review of Research in Open and Distributed Learning Volume 20, Number 1

February - 2019

\title{
An Analysis of the Journey of Open and Distance Education: Major Concepts and Cutoff Points in Research Trends
}

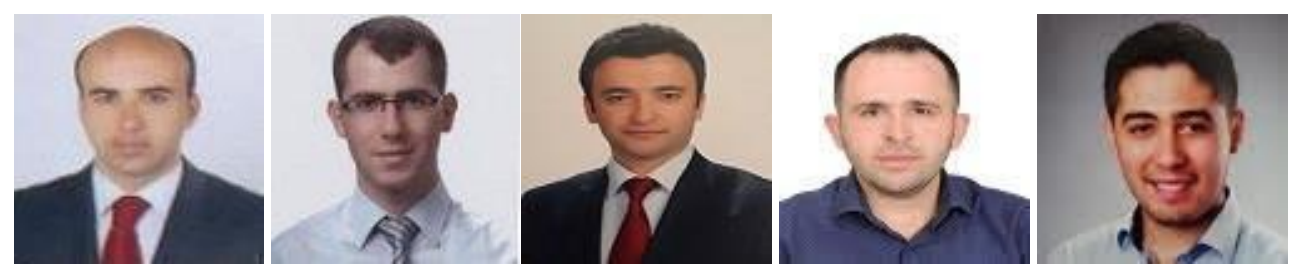

Ünal Çakıroğlu ${ }^{1}$, Mehmet Kokoç ${ }^{1}$, Seyfullah Gökoğlu², Mücahit Öztürk ${ }^{3}$, and Fatih Erdoğdu1

${ }^{1}$ Trabzon University, ${ }^{2}$ Kastamonu University, ${ }^{3}$ Aksaray University

\begin{abstract}
In an effort to understand trends in open and distance education more comprehensively, this study aims to identify the research trends, major concepts, and cutoff points in the articles published between 2009 and 2016. From five major peer-reviewed journals, a total of 989 articles were analyzed through a systematic literature review process using content analysis. The articles were coded based on the following three categories: level, topics, and sub-topics. The results indicated the followings: (1) emerged main themes in the articles were foundations of open and distance education, instructional process, and effects of applications; (2) there was an upward growth in the publishing of the articles on massive open online courses, open educational resources, and students' perspectives; (3) new pedagogical approaches and online learning design played a triggering role in the research topics; and (4) technological and pedagogical developments between 2011 and 2012 had an influence on the tendency of the articles. In addition, we explored cutoff points so that they may provide insights and valuable hints for researchers to design new studies in open and distance education field. Discussions about the gaps in the state-of-the-art trends and directions about future research were also included.
\end{abstract}

Keywords: open and distance education, review study, research trends, content analysis 


\section{Introduction}

Systematic review studies and content analysis can provide researchers with a guideline: shed light on further research and encourage initiatives by synthesizing papers in any field. As a roadmap, these studies provide insightful knowledge about research trends and important topics in the field (Shih, Feng, \& Tsai, 2008). They provide an opportunity to follow up a clear research direction for researchers. Since the field of open and distance education (DE) is a growing area, review studies in this field can help to understand trends and research topics. Considering media, platforms, and pedagogical models, systematic reviews in open and DE field are increasing. However, there are still a few review studies that focus on the topic trends, cutoff points, and gaps in open and distance learning research. In this regard, this study aims to review current topic trends and explore potential research directions in the field. In doing so, it is hoped that the study will contribute to a deeper understanding of advancement in the field of open and distance learning by providing valuable suggestions for future research and practice.

\section{Open and Distance Learning}

As a kind of governmental and official learning, open and distance learning takes place in diverse contexts through major educational elements by linking pupils, supplies, and teachers to one another via various communication media (Moore, Dickson-Deane, \& Galyen, 2011; Simonson, Smaldino, Albright, \& Zvacek, 2011). Keegan (1996) defined open and distance learning as an umbrella for online learning, internet-based learning, e-learning, and so on. In the definition, interactive communication technologies, which form the learning environment, are the focal point. In this sense, with the rapid developments in technology from postal service to a broad internet network, people have encountered different forms of open and DE over the years. For the last three decades, a dramatic shift has occurred in the open and distance learning field. Open learning, e-learning, online learning, web-based learning, internet-based learning, and distance learning have often been studied and reviewed in the context of open and DE for years (Lowenthal \& Wilson, 2010).

Previous research studies investigated the state of the research in the field and the rise and fall of the paradigms from the diverse viewpoints. Review studies fall behind the changes in this fast changing field (Petticrew \& Roberts, 2008); therefore, this systematic review study analyzed various studies in primary journals to outline the situation of open and DE. In line with this aim, we analyzed the previous review studies first. For instance, Lee (2017) noted the remarkable developments including new technologies or new ways of using technology in the past 20 years.

\section{A Quick Look at the Field Over the Past 30 Years}

There have been major developments in the field of open and DE over the past 30 years. Figure 1 provides an at-a-glance view of these developments beginning in the 1990 . 


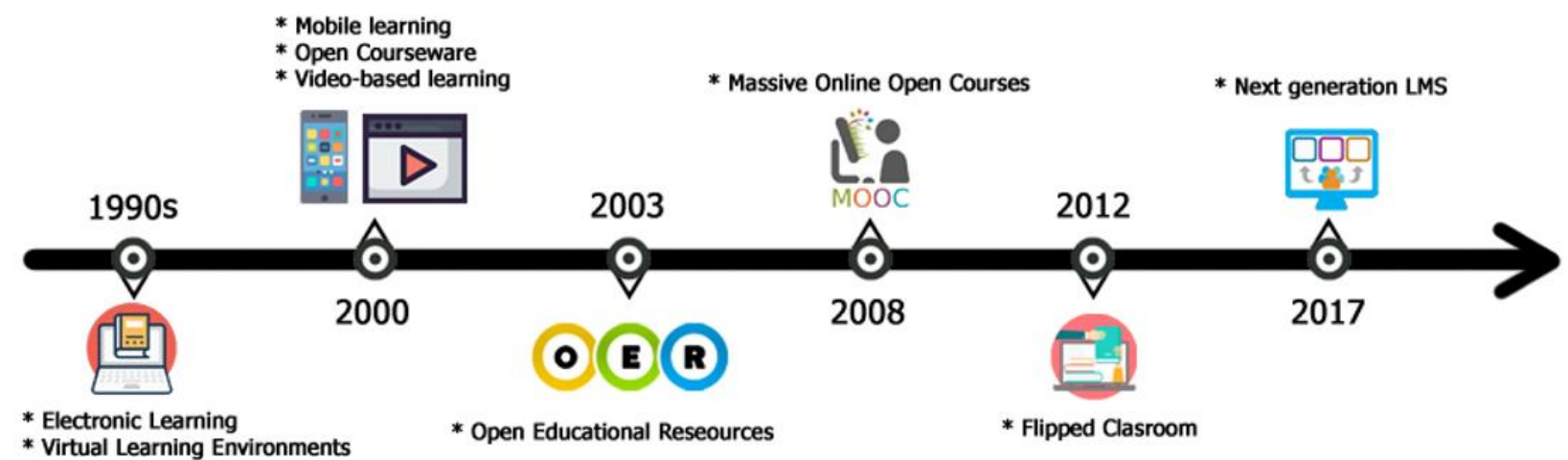

Figure 1. The emergence of computer and internet technologies.

Figure 1 begins with the emergence of computer and internet technologies in the 1990s. After that, the spread of computer and internet technologies led to a number of transformations in the field of open and DE. Following this spread, the concept of e-learning, which is supported by electronic hardware and software as a synchronous and asynchronous tool, emerged. With the development of Web 2.o technologies in 2004, users gained the ability to use online content to produce their own content. In particular, with the introduction of synchronous technologies (e.g., chat rooms, instant messaging, and video conferencing) at the basic level, human feel or real-life experience was added to the online experience of DE. Considering the fact that technology brings about high learning effectiveness, quality of interaction, and more learnercentered approaches in education (Bates, 1997), these developments in Figure 1 can be considered valuable in creating learner-centric environments for open and DE.

After the early 2000s, with the emergence of mobile technology, m-learning developed in education, which provides learners with more flexible, independent, and individualized learning opportunities enabling them to learn independent of time and place. This flexibility has led to a significant turnaround for learners and instructors. In addition, a significant increase in research on video-based learning, especially after 2007, attracted attention for a while in open and DE applications (Giannakos, 2013). In this period, Massachusetts Institute of Technology (MIT) introduced the "OpenCourseWare model" to the field of open and distance education by opening up approximately 2000 of their courses online (Atkins, Brown, \& Hammond, 2007). The idea of openness gained a different dimension in 2003 when the Open Educational Resources (OER) movement emerged. In line with these developments, a large demand for online learning brought important issues to light regarding student support and access to educational resources for open and distance learners. For this reason, the emergence of OER in 2008 have allowed researchers to implement distance practices in a different way by accessing them.

In order to meet the needs of online learners and instructors easily, the institutions have begun to use Learning Management Systems (LMS). LMSs were introduced as integrated systems that enable managing instructional materials, monitoring both learners and teachers, and individualize instructional processes. At the beginning, LMSs were only capable of presenting the course content in the form of basic presentations, but with the advances in learning technologies, LMSs have been transformed into their new forms. In recent years, a new kind of LMS, called next-generation LMSs, has provided new services for 
administrating content, learners, and interactions (Adams Becker et al., 2017). This may be considered as a paradigm shift in the field of open and distance learning. Next-generation LMSs suggest flexible configurations and a more personalized and formative evaluation structure.

Additionally, it was the first time that video-based instruction had been implemented throughout a course. For example, the chemistry teachers Jon Bergmann and Aaron Sams, ensured that the students who missed the class were able to access all issues discussed in the class by using videos (Tucker, 2012). Following this development, researchers have started to evaluate the effect of both technological and pedagogical dimensions of online learning on learning outcomes. Researchers still keep studying to explore new ways to design and utilize open and online courses in a distributed learning environment.

\section{Review Studies on Open and Distance Education Field}

Looking through various lenses, some review studies put forth developments in the field of open and DE. For instance, one review study including the studies in DE from 1990 to 1999 pointed out that the research studies are dominated by the design issues, learner demographics, active learning strategies and interactions. So there is a need for focusing other issues about DE (Berge \& Mrozowski, 2001). Researchers analyzed studies based on Sherry's (1996) categorization system that constructed 10 research issues as follows: 1) redefining the roles of key participants; 2) technology selection and adoption; 3) design issues; 4) strategies to increase interactivity and active learning; 5) learner characteristics; 6) learner support; 7) operational issues; 8) policy and management issues; 9) equity and accessibility; and 10) cost/benefit tradeoffs. They concluded that most of the studies in the field of DE focused on the impact of individual technologies (Berge \& Mrozowski, 2001). In a recent study, Zawacki-Richter, Alturki, and Aldraiweesh (2017) categorized research issues into 15 research areas within three main levels: 1) macro level (DE systems and theories), 2) meso level (management, organization, and technology), and 3) micro level (teaching and learning in DE). Based on their findings, they explored three periods relevant to research areas for the last 15 years: 1) online learning and DE institutions (2000-2005), 2) widening access to education and online learning support (2006-2010), and 3) the emergence of MOOCs and OER (20112015).

Although various perspectives guided the review studies, the characteristics of publications provided a key role in the effect of these reviews. In addition, the journals taken into account in the reviews were another factor in making these reviews considerable. In this light, a continuous supply-demand cycle between the researchers, the practitioners, and the organizers remains dynamic considering the rapid changes of distance learning technologies and practices.

\section{Need for Study}

As an evolving interdisciplinary field, the DE field is attempting to conform to steady changes in technology and pedagogy. As educational change is inevitable and pertinent, we are endeavoring to discover and organize the most appropriate method for open learning and DE in the current learning environment. With the growing demands of instructors and learners, it is imperative to grasp trends and concerns of DE to keep up with these developments. As an evolving interdisciplinary field, DE is trying to conform to these steady changes. Accordingly, this study may pave the way to perceive and clarify recent DE dynamics 
through academic reports by supplying an inclusive silent evidence list in this field (Hodder, 1994). By making the research trends visible, research gaps can be located and future research can be planned to enable the shift. Understanding this shift may help instructional designers, instructors, or policymakers for short and medium term planning in this area.

\section{Problem}

This review study analyzes the research and educational implementation trends in DE. In the context of five major open and DE journals, we focused on the main research topics in publications and examined how the manuscript's scope or coverage changed between 2009 and 2016. In order to address the most common research areas and to determine the potential gaps in DE research, the following questions were formulated:

1. What are the trends in research topics of distance learning research articles published from 2009 to 2016 ?

2. What are the major concepts and cutoff points in the research articles reflecting the development of DE?

By answering the research questions, this paper will make a contribution to the description of the field of DE through organization, designing, implementing, and evaluating.

\section{Method}

In order to ensure a systematic review process, we conducted a content analysis by following steps suggested by Cooper (2010) and Oliver (2014). First, we formulated the research problems, then we defined the criteria for searching the literature and a strategy for extracting necessary information from studies, analyzed the findings, interpreted the evidence, and at the end, we reported the findings. Content analysis was implemented because editing, classification, comparison of texts, and gathering theoretical results from texts were performed through content analysis (Cohen, Manion, \& Morrison, 2007). Content analysis presents important structures for the types, qualities, and distinguishing features in text structures by numerical definitions, providing a bridge between numerical formatting and qualitative analysis (Bauer, 2003). In addition, in this research, similar data were transformed into an interpretable form by combining them in a systematic way with specific concepts and themes through content analysis.

\section{Sample}

The research sampled articles published between 2009 and 2016 to reveal research trends in DE emerging from scholarly publishing in five popular journals: American Journal of Distance Education, Distance Education, European Journal of Open, Distance and E-Learning, The International Review of Research in Open and Distributed Learning, and Open Learning: The Journal of Open, Distance and e-Learning. The following criteria were taken into consideration in the selection of the relevant journals:

- To focus only on open and DE publications, 
- To be in the status of an internationally recognized journal that is searched by leading databases in the field of education (SSCI, ERIC, DOAJ, EBSCO), and

- To have at least 10 years of publication history.

Some other studies have also been published in other key journals about educational technologies. However in this study, the journals directly having the scope of open and distance learning have been particularly selected to reveal the changes in the topics of DE. For instance, IRRODL, one of the major journals in DE area, publishes articles including both theoretical and practical issues of DE through various perspectives. The year 2009 was taken as a cutoff point because previous review studies were considerably available up to this time. On the other hand, Web 2.0 technologies, LMS, and synchronous environments, which developed after 2009, are believed to have radically shifted the structure of DE (Nasiri \& Mafakheri, 2015). All research articles $(\mathrm{N}=989)$ published in the five selected journals between 2009 and 2015 were reviewed. Figure 2 illustrates the publication dates and journals reviewed.

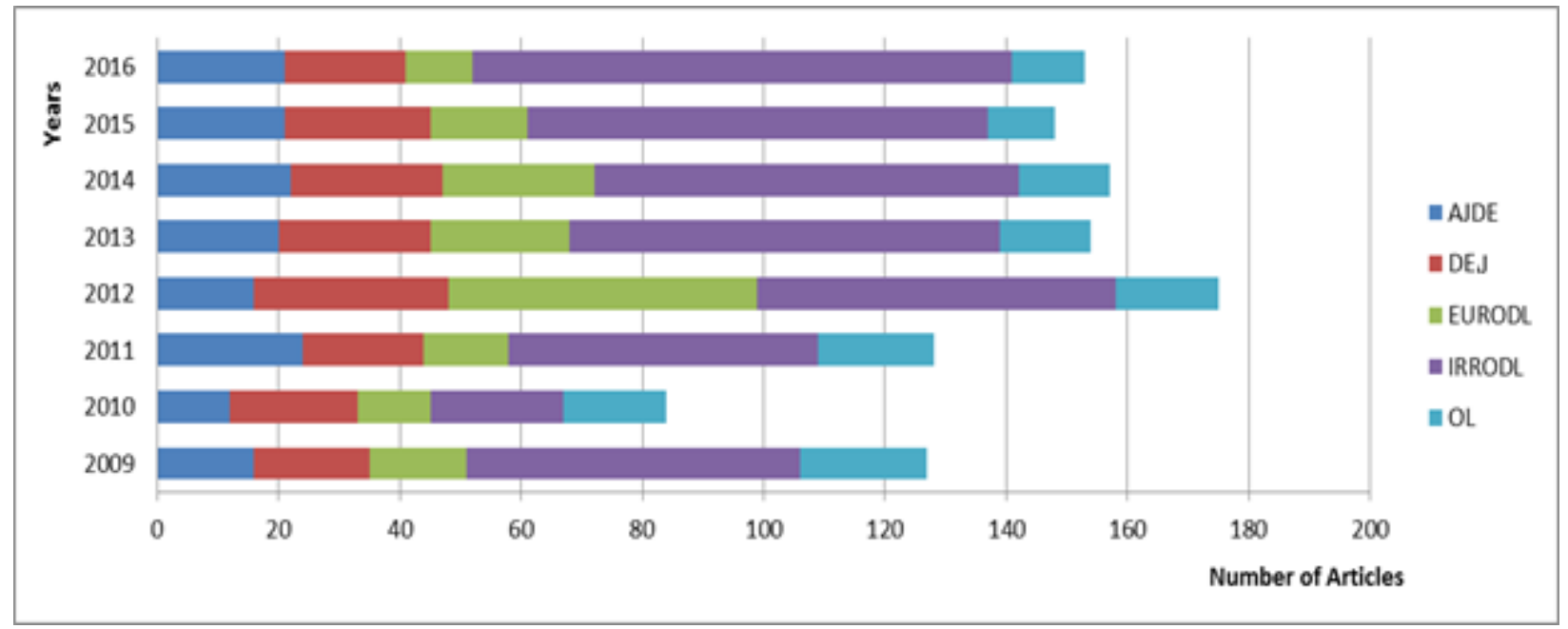

Figure 2. Distribution of the articles by the journals and years.

\section{Process}

By developing themes established in the frame of the related literature and the criteria determined by the researchers, the content of the articles in selected journals were coded according to these themes and were reported on using descriptive analysis.

Although many review studies focus on the abstract sections of the studies, the abstracts alone were considered insufficient for the desired analysis in this study. To address this, the authors chose to review titles, keywords, method sections, and full-text manuscripts where deemed appropriate. The articles were analyzed within the framework of the classification scheme developed by the researchers (Figure 3). The algorithm below is followed during this classification. 


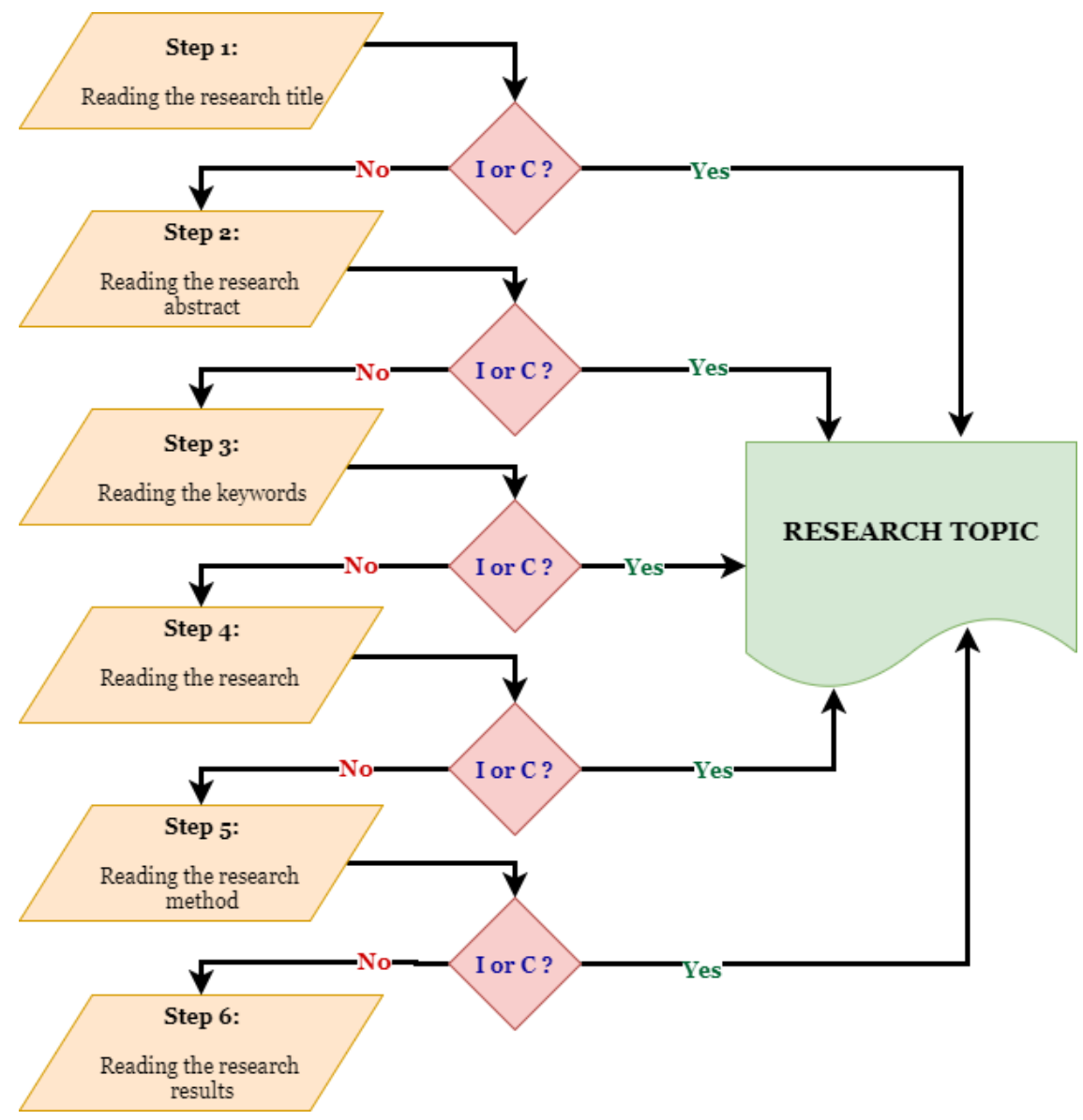

I: Indicator, C: Clue

Figure 3. The research topic determining the process.

In the process of analyzing articles, the initial analysis was carried out together with two faculty members who were experts in the field in order to assist the researchers and ensure a correct analysis. In order for the analysis to be carried out in a systematic manner, each researcher reviewed the articles they had examined as shown in Figure 3. In this review process, the research title was read in the first step if any indicator (I) or clue (C) for the predetermined topic in the title was specified. In the case when the researcher could not determine any clue or indicator in the title, the steps shown in the figure were put in process.

The classification of the articles was completed by the researchers in three stages through Google Documents to make it easier to work together. In the first stage, each researcher made the necessary markings on the web-generated table of the data for the articles s/he examined. In the second stage, the researchers made data entries on the tables about the articles they analyzed and these data were then checked by other investigators. In the third stage, an attempt to resolve any differences in opinion was completed through the consultation of expert researchers, providing the internal validity and reliability for the study. When some of the manuscripts addressed more than one topic or reflected more than one major 
concept, all of the related cells were assigned. The initial inter-rater reliability at the end of the process was calculated as 0.8 .

\section{Data Analysis}

Two lecturers and three $\mathrm{PhD}$ students worked together in the content analysis. The contents of the articles were read and categorized by the researchers as displayed in Table 1.

Table 1

Subject Field Decision Process

\begin{tabular}{|c|c|c|}
\hline Criteria & Sample & Topic \\
\hline$\overline{\text { Title }}$ & $\begin{array}{l}\text { Mobile Usability in Educational Contexts: What have we learnt? } \\
\text { (Kukulska-Hulme, 2007) }\end{array}$ & Mobile Learning \\
\hline Abstract & $\begin{array}{l}\text { "This paper considers electronic interaction between learners and module } \\
\text { facilitators and draws on a small study that evaluated the experiences" } \\
\text { (Morgan, 2006, p.1). }\end{array}$ & Interaction \\
\hline Keywords & $\begin{array}{l}\text { Interactive computer learning, virtual schools, online learning, e-learning } \\
\text { (Russell, 2006). }\end{array}$ & Virtual \\
\hline Introduction & $\begin{array}{l}\text { "As UT embarks on this ambitious project, it can draw on many } \\
\text { experiences and lessons learned from its history....These lessons are based } \\
\text { on earlier experiences with web-based administration and instruction over } \\
\text { two decades"(Luschei, Dimyati, \& Padmo, 2008, p. 165). }\end{array}$ & $\begin{array}{l}\text { Web } \\
\text { Applications }\end{array}$ \\
\hline Method & $\begin{array}{l}\text { "Higher total scale scores on this scale indicate more positive perceptions } \\
\text { toward online course communication and collaboration" (Bernard, Paton, } \\
\text { \& Lan, 2008, p.4). }\end{array}$ & $\begin{array}{l}\text { Communication } \\
\text { \& Collaboration }\end{array}$ \\
\hline Results & $\begin{array}{l}\text { "Finally, most faculty members interviewed were generally satisfied with } \\
\text { their work" (Ariadurai \& Manohanthan, 2008, p.9). }\end{array}$ & $\begin{array}{l}\text { Instructors } \\
\text { Perspectives }\end{array}$ \\
\hline
\end{tabular}

\section{Results and Discussion}

As demonstrated in previous studies, the results of this study indicate that distance education technologies are expanding at an extremely rapid rate. It is observed that with the development of the DE tools for asynchronous and synchronous communications, learner-centered education approaches are increasingly used in DE. Hence, several technologies are described and explained for "whats" and "hows" of the design and application of DE activities in real time and blended forms. It was observed that a large quantity of explanatory or descriptive studies in the defined period dealt with attitudes, interests, or assessments of experienced colleagues in the field of distance education. It was also seen that quantitative, qualitative, or mixed research designs were conducted in the DE field similar to many other research fields. However, since we are specifically interested in the topic trends, we omitted the methodologies of the studies and all studies were considered at the same value. From a different perspective, we considered the DE development 
process as a typical research process, which includes theory, implementation, and results. In accordance with this, we searched for the topics in order to define the trends and the cutoff points.

\section{The Trends in Research Topics in Distance Learning}

The investigated studies were evaluated according to the main themes in the journals and shown in the graphs according to the numbers included in the topics. The topics that are considered to be closely related to each other in the main themes were colored in the form of sub-themes. In this way, the trends of the main topics in DE studies over the years are outlined in Figure 4.

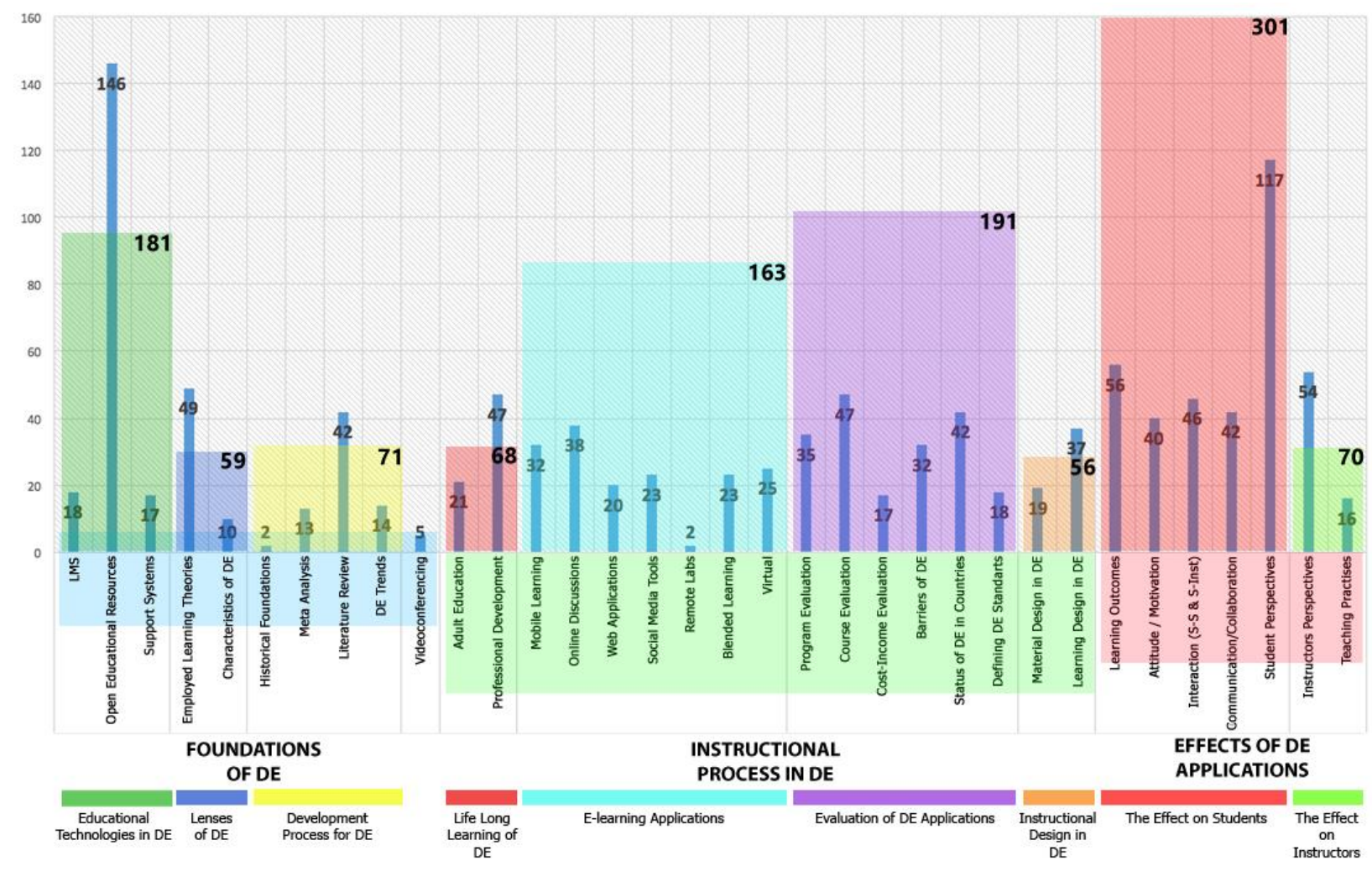

Figure 4. The trends in research topics in distance learning articles published from 2009 to 2016.

Figure 4 indicates that when studies related to the Levels of Foundations of DE between 2009 and 2016 were analyzed, the Open Educational Sources studies were observed to be more prevalent than all other themes ( $n=146)$. Similarly, this theme was also identified as open educational resources (OER) in the study conducted by Bozkurt et al. (2015), which determine the research trends in DE studies between 2009 and 2013. In the study, 861 articles were analyzed by keywords and it was determined that OER was the first among 40 most commonly used keywords. Considering that keywords are descriptive in terms of articles, it can be said that the theme of open educational sources is, and remains, one of the trend topics in distance learning. Another notable finding is that more papers related to employed learning theories $(n=49)$ and 
literature review $(n=42)$ were published after the studies on open educational sources. In another study about the DE trends between 1998 and 2007 (Davies, Howell, \& Petrie, 2010), Employed Learning Theories theme was included in the study under the subject of DE theory and a small number of studies were found to have been conducted at that time. However, in recent years, there has been a considerable increase in the research conducted within this theme. Even if the number of articles is relatively low in our review, this result is consistent with the findings reported by other research on distance educational trends published in recent and partly different journals between 2009 and 2013, and 2008 and 2015 (Bozkurt et al., 2015; Bozkurt, Akgün-Özbek, \& Zawacki-Richter, 2017). In addition, an emerging and frequently studied field in the macro level under the title of Theories and Models was identified by these researchers.

In addition, it is noteworthy that the studies on historical foundation and video conferencing between 2009 and 2016 were significantly limited when compared to other studies. This suggests that the development of distance education technologies is used in the application of some technologies (video conferencing) but it is limited in the research area. When the sub-headings of instructional process level in DE between 2009 and 2016 were examined, it was found that articles on professional development $(n=47)$, course evaluation $(n=47)$, and status of distance education in countries are clearly more than other themes. However, it is noteworthy that the topics studied on the instructional process at the DE level are distributed in a balanced manner, and the number of remote labs $(n=2)$ publications seems to be very low. Although it appears possible to reflect different student or teacher experiences, remote labs do not seem to attract much researcher attention. Similarly, in this framework, in a systematic review of online learning environments, Martin, Ahlgrim-Delzell, and Budhrani (2017) suggest that studies discussing online learning environments within countries are increasing and there is a need for research on remote labs.

During the eight-year period, the most frequently studied subjects under the effects of DE applications level were found to be related to the student perspectives $(n=117)$, followed by learning outcomes $(n=56)$, and instructor perspectives $(n=54)$. During this period, the topic of teaching practices $(n=16)$ was found as the least studied topic. Similarly Davies, Howell, and Petrie (2010) pointed out that student perspectives were the most studied topic in DE. In the same study, the instructor perspectives theme was evaluated in the context of faculty issues and it was determined as one of the most frequently searched topic areas.,

Overall, our review found that the main themes were foundations of DE, instructional process, and the effects of DE. The basic frameworks dealing with interactions, communications, people, or organizations such as transactional distance, the community of inquiry, andragogy, or industrialization, are taken into consideration in many of these studies. The number of studies carried out in these areas is close to each other; however, the distribution of them differs according to years. The research status of the identified themes over the years is shown in Figure 5, Figure 6, and Figure 7. 
An Analysis of the Journey of Open and Distance Education: Major Concepts and Cutoff Points in Research Trends Çakıroğlu, Kokoç, Gökoğlu, Öztürk, and Erdoğdu

\section{Number of studies}

\section{Foundations of DE}

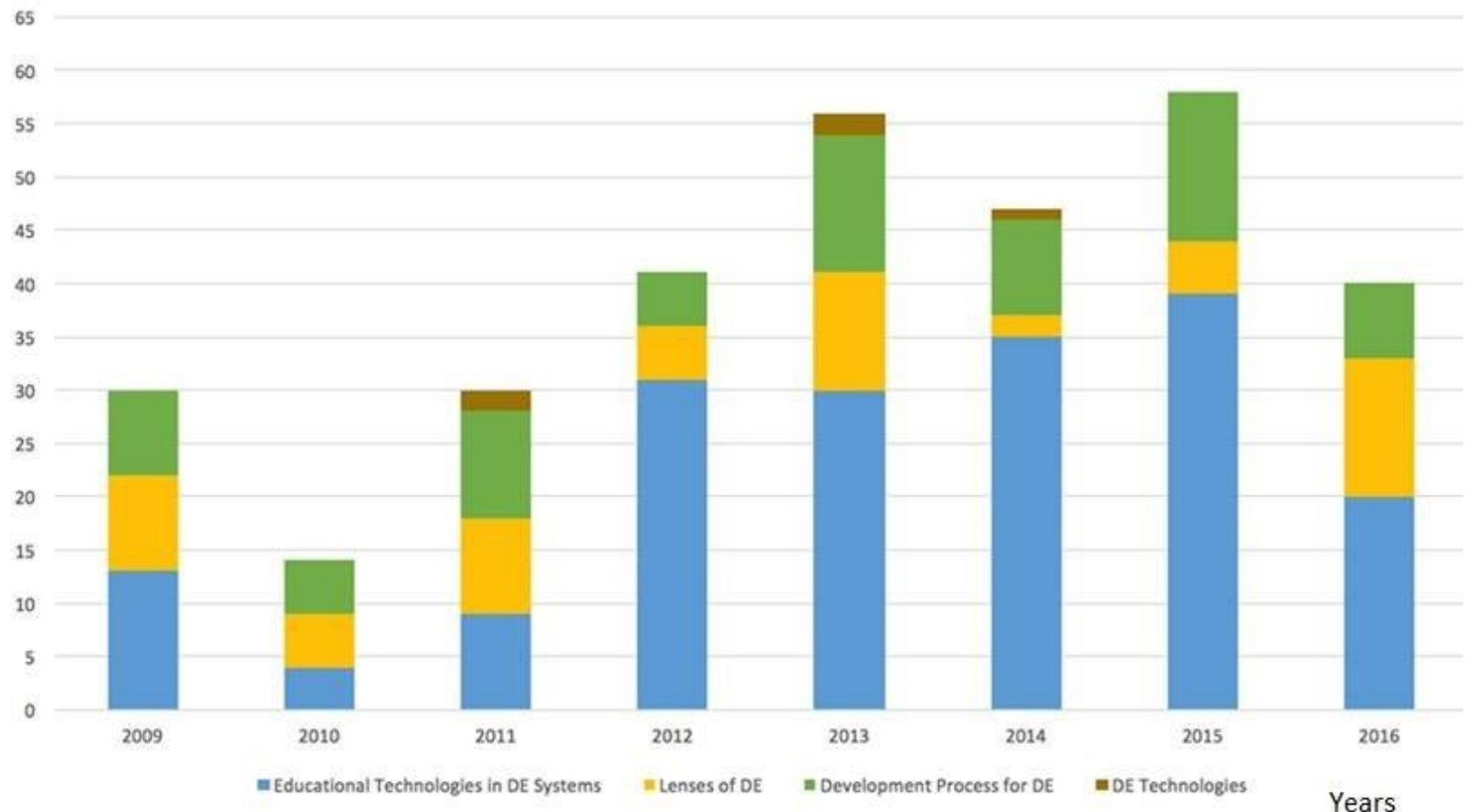

Figure 5. Trends in the main theme of Foundations of DE.

Number of

studies

Instructional Design Process in DE

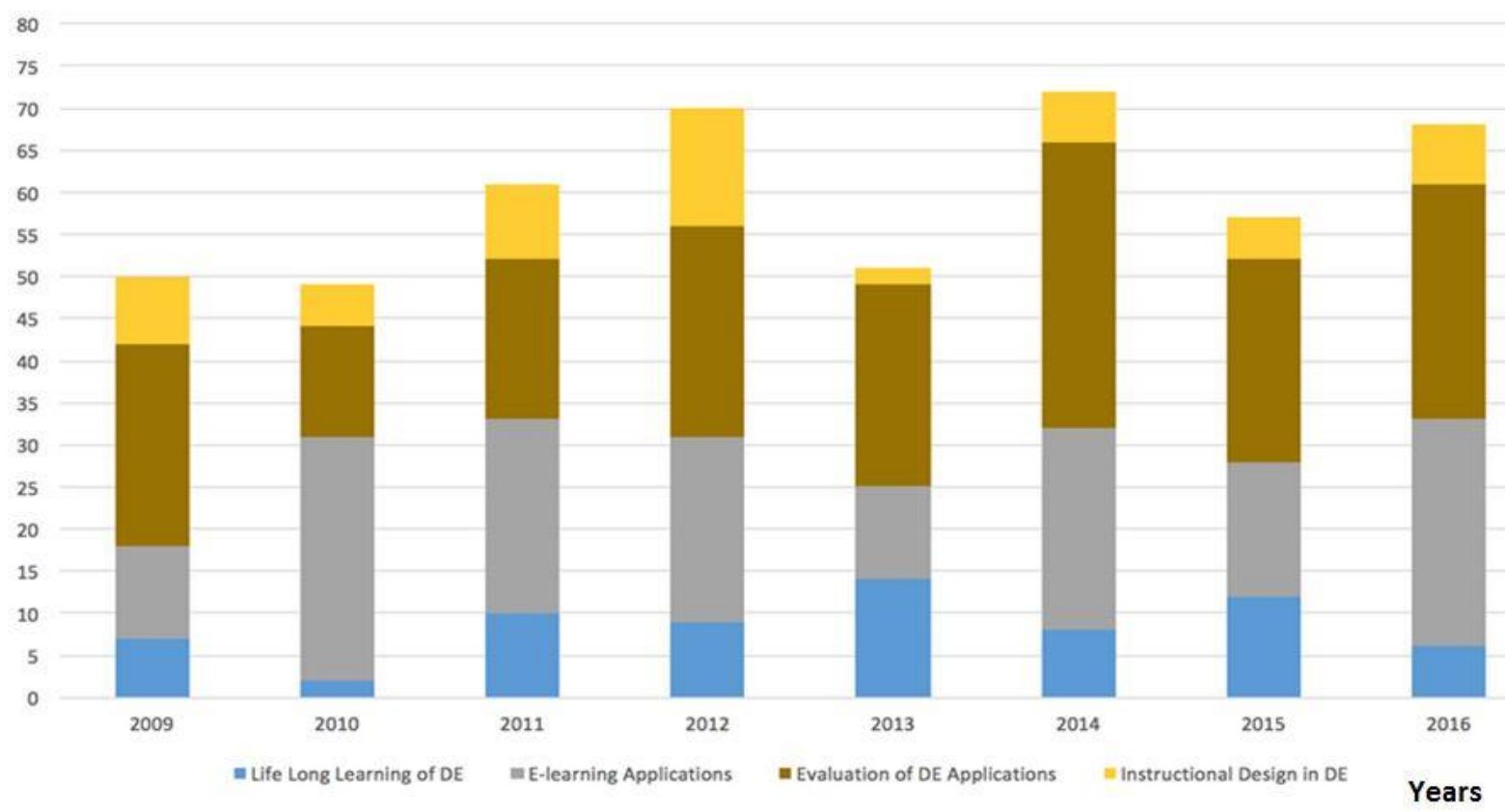


Figure 6. Trends in the main theme of Instructional Design Process in DE.

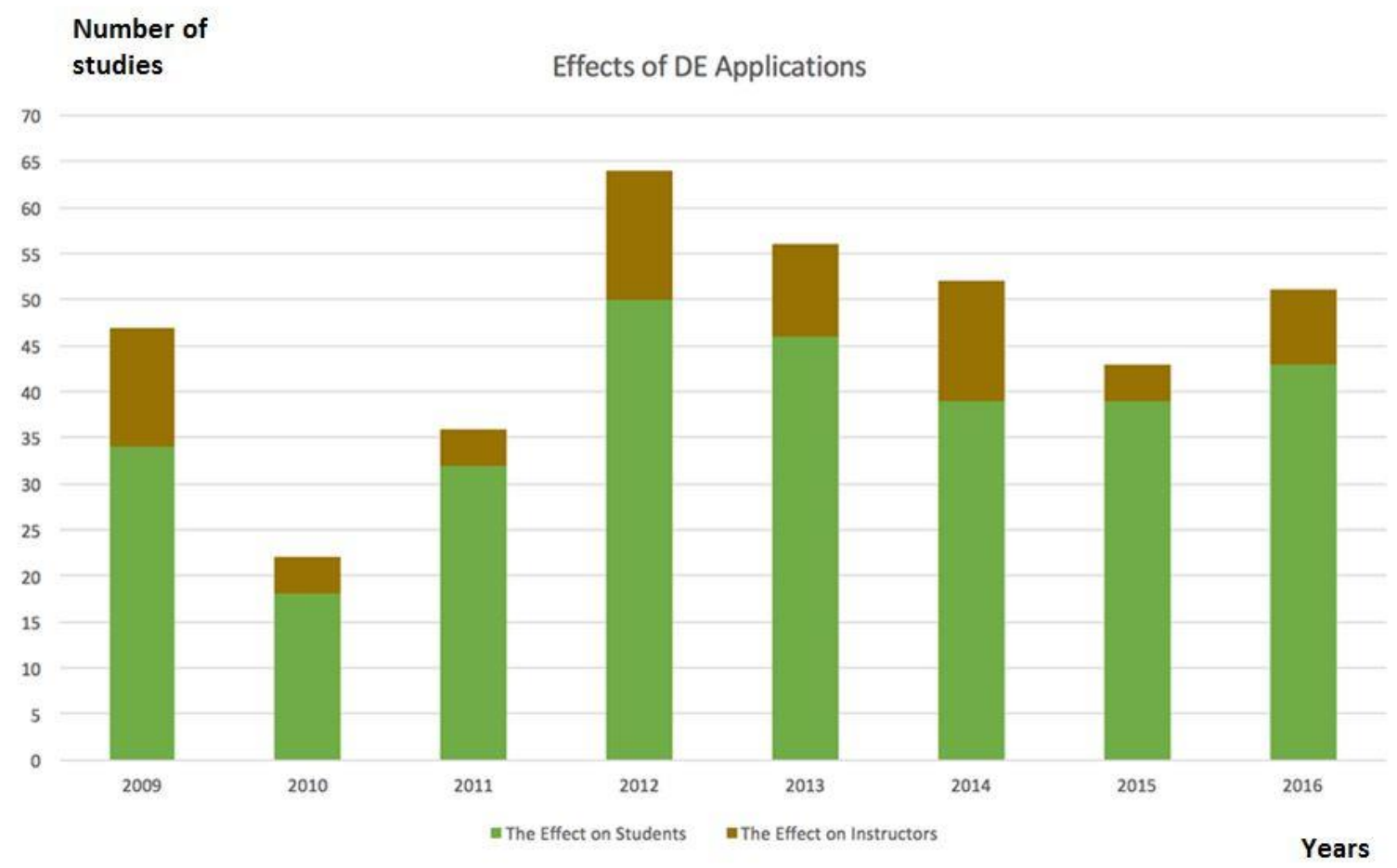

Figure 7. Trends in the main theme of Effects of DE Applications.

As seen in Figure 5, when examining the studies between 2009 and 2016, it was found that the instructional process in DE topic with its sub-topics is the most frequently studied topic ( $\mathrm{n}=478)$. On the other hand, foundations of DE, together with its topic and sub-topics, are less studied than the other levels $(\mathrm{n}=316)$. When the conducted studies were evaluated in the context of topics, the effect of DE on students was determined as the major studied topic $(n=301)$. Surprisingly, DE technologies draw attention as the least studied topic $(n=5)$. On the other hand, open educational sources and student perspectives seem to be prominent studies compared to other sub-topics.

\section{Major Concepts Studied in the Development Process of DE}

Considering the sub-themes, we also determined the ratios of the topics in the whole. Hence, Figure 8 shows sub-topics studied extensively. 


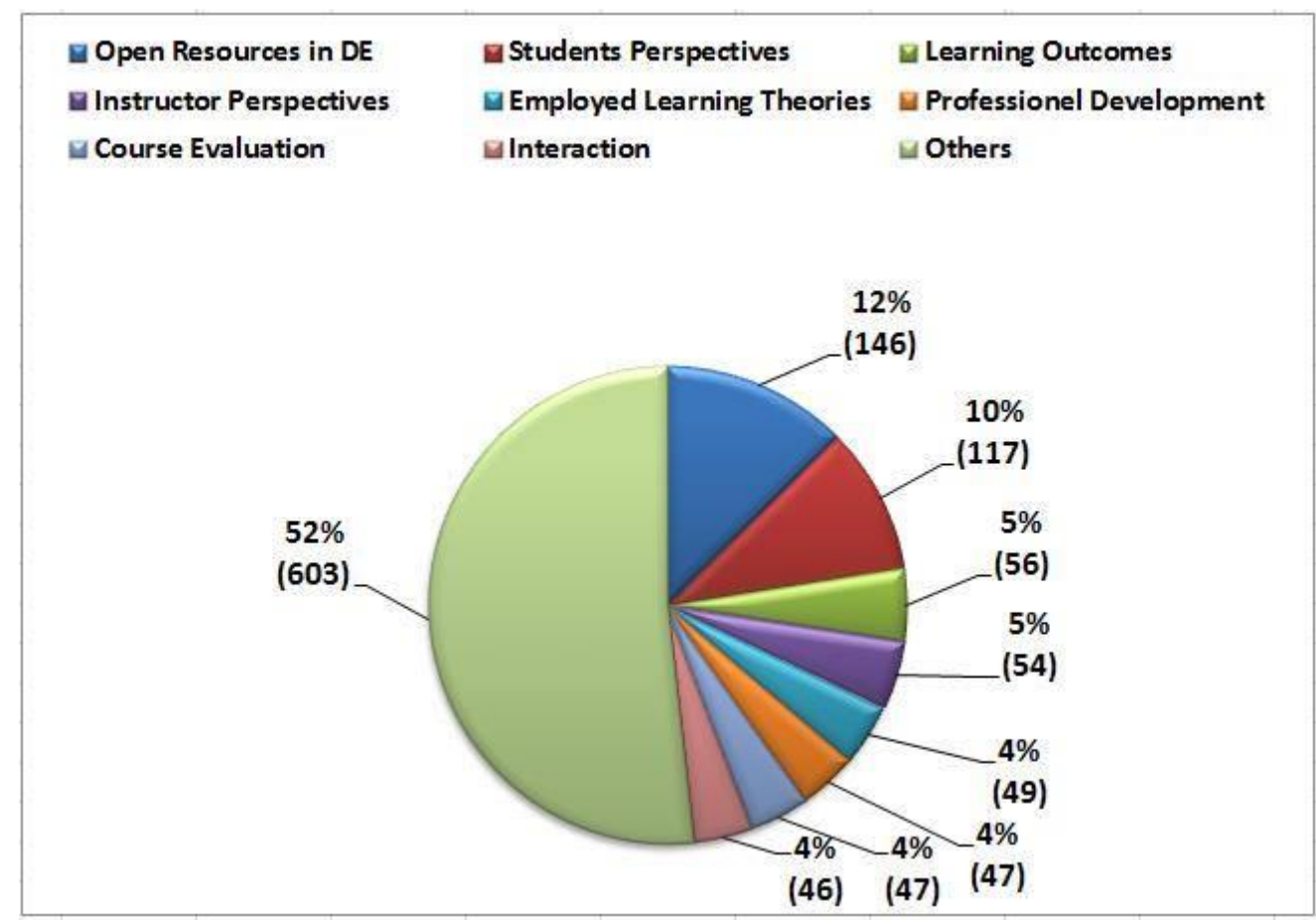

Figure 8. The major concepts studied in the development of DE.

Figure 8 indicates that open source in DE is one of the dominant sub-topics $(n=146)$ followed by student perspectives sub-topic $(\mathrm{n}=117)$. It is seen that these two subjects are much more studied in the field of DE than the others between the years of 2009 and 2016. Additionally, interaction $(n=46)$, course evaluation $(n=47)$, and professional development $(n=47)$ are the least studied topics. Similar to the findings of the study, Bozkurt et al. (2015) observed that open educational source keywords were most commonly referred between 2009 and 2013. Similarly, the study of Bozkurt, Keskin, and de Waard (2016) showed that MOOCs increased rapidly after 2012. In addition, Davies et al. (2010) drew attention to the fact that the most frequently studied topic in the theme of DE between 1998 and 2007 was student issues. In this study, this theme is called the students' perspective. Although this study observed only a few studies on interaction, Bozkurt et al. (2015) noted that the number of studies on interaction is high.

\section{Cutoff Points in the Period of 2009-2016}

Reviewing the literature on open and DE in terms of the topics can contribute to the understanding of key characteristics that shape the developing trends in open and DE. Therefore, the identification of cutoff points that explain the studies in the field of open and DE has constituted an important part of this study. Zawacki-Richter, Bäcker, and Vogt (2009) examined research trends in DE from 2000 to 2008 and found that studies focused mostly on interaction and communication patterns in computer-mediated communication, instructional design issues, learner characteristics, and educational technology. Although trends are addressed in this study and other studies (Bozkurt et al., 2015; Davies et al., 2010), no definitive evidence has been put forward regarding their evaluations of the transitions to other topics. 
When the studies discussed in this review study are taken into consideration based on the topics, it is interesting to note that the number of studies on educational technology in DE systems has a significant increase since $2012(n=31)$ than the previous year. The rise of open educational resources with MOOCs, which started to become widespread throughout the world in 2011, can be seen as a source of this increase. In fact, MOOCs first emerged in 2008 with the increase in using open educational resources and practices movement. After 2008, the most commonly known commercial and/or free platforms like Coursera, edX, and Udacity were introduced, with a high interest in MOOCs. Therefore, in this period, widely used MOOCs brought together many open research questions for creating effective MOOCs and understanding the effects of MOOCs (Diver \& Martinez, 2015). Moreover, the importance of MOOCs and OER was highlighted with the publishing of special issues. As an example, IRRODL published five special issues on MOOCs and OER from 2011 to 2015. The titles of the special issues which are closely related to higher education are as follows: European perspective on MOOCs (2015); OER, Opening access to knowledge (2013); and, Prior, experiential, and informal learning in the age of information and communication technologies (2011). In this context, focusing on the studies about MOOCs and OER, the study titled as "MOOCs, OERs and interactive learning" summarized the developments in DE for the time period between 2010 and 2014 through an analysis of titles and abstracts of publications in the journal Distance Education (ZawackiRichter \& Naidu, 2016). Similarly, another review study by Zawacki-Richter, Alturki, and Aldraiweesh (2017) was published by considering the articles in the journal of IRRODL about the five-year (2011-2015) emergence of MOOCs and OER period. Moreover, Horizon Report has predicted that open content will play an important role through the same period (Johnson, Laurence, Levine, Smith, \& Stone, 2010). In this five year period, one reason for the increasing in the research studies related to MOOCs is drawing attention to OER and open content. As a consequence, the openness idea in these years can be considered as a remarkable change in DE. Hence, the emergence of MOOCs and OER was taken as a cutoff point in the journey of DE.

Studies at the level of the effects of DE applications on learning and teacher-impact-related studies showed a significant increase in $2012(\mathrm{n}=64)$ compared to 2011. This increase is consistent with the increase in 2012 in other topic studies that continued until 2016. When examining the studies of teachers, which peaked in 2012, the focus was observed to be on learners' characteristics, learner and instructor perspectives, and the relevance of DE applications to learning. This result is in accordance with a recent review study by ZawackiRichter, Alturki, and Aldraiweesh (2017) indicating that learner characteristics and instructional design were important research areas between 2011 and 2015. On the other hand, our result indicates a shift in the understanding of how to use emerging technologies for open and distance learning around the year 2012. In this case, the widespread use of emerging technologies and advanced platforms has created a significant gap between the potentials of these technologies and how these technologies affect the learning processes pedagogically (Bishop \& Elen, 2014; Veletsianos, 2010). In addition to the prevalence of new technologies, how to effectively design learning and instructional processes for effective contributions to a students' learning has been an important question in the development of open and distance learning (Simonson, Smaldino, \& Zvacek, 2015). In this context, the triggering role of the pedagogical approaches (flipped classroom, connectivism, self-directed learning) and learning design comes to the forefront. Overall, designing learning environments and evaluating learning performances were the focus points in the year 
2012 (Kovanović, Joksimović, Gašević, Siemens, \& Hatala, 2015). Therefore, "online learning design and pedagogy" might be regarded as an important topic for 2012.

On the other hand, there is a significant decrease in the studies on the foundations of DE in 2016, yet only a gradual decline of the theoretical studies on DE. One of the reasons for the decrease in the number of these kinds of studies is that the necessary definitions have been previously provided and approved by the researchers and the new DE theories or models are less needed. No publications were published in the journals in 2016 covering the foundations of DE, in the subtopics of the characteristics of DE, historical foundations, and DE trends. At this point, it can be predicted that the issues related to the foundations may decrease in the following years. In 2016, in contrast to foundations, surprisingly, there was an increase in the subtopics of the status of DE in countries and communication/collaboration. These findings indicate that studies about the comparison of DE in different cultures and cultural integration may increase. Also, one can assume that new evaluations about interactions and communications techniques in DE will be addressed more after 2016.

In the topics of e-learning application, it is seen that the number of studies in mobile learning and online discussion subtopics has increased consistently since 2011. One reason for the continuous increase in the research on mobile learning subtopic may reflect the wide application of mobile learning. In addition, another reason for the continuous study of online discussions is the tendency of researchers to evaluate the online environments through constructivist student-centered approaches. Moreover, the course evaluation studies were they continued to be studied between 2009-2016, however, the number of those studies were limited. This may be due to the researchers' emphasis provided on the quality of distance learning applications rather than the comparison of face-to-face and distance learning implementations.

In sum, MOOCs and OER, online learning design and pedagogy topics emerged in 2012, and the topics related to the theoretical perspectives in 2016 may be considered a change from 2009 to 2016.

\section{Conclusion and Recommendations}

The results from this systematic review generalize the findings in the main concepts and cutoff points from 2009-2016 to inform distance education researchers, instructors, and administrators in their future online learning efforts. We have critically discussed major trend topics regarding their cutoff points and major concepts related to studies on open and distance education. Despite the limitations, this study contributes to the open and distance education field by focusing on the theoretical and practical approaches in relation to the technological developments and expectations of learners, instructors, and institutions. Considering the findings of this research, the following implications may direct future research. This study presented the most frequently studied research areas such as open educational resources and student perspectives in the field, yet there has not been considerable research on study topics such as distance education technologies, support systems, teaching practices, and pedagogical approaches. Based on our results, we can say that additional research is needed to have a better understanding of the relation between paradigm shifts that occur in open and distance education and how to design and deliver online courses effectively. 
Also, future studies could investigate online teaching skills and the effect of distance education on teachers more deeply by considering theoretical and practical changes in the last years. Although it may be considered that they might provide valuable insights into the instructional design for online environments, the number of studies in some topics, such as remote labs and virtual environments, is shockingly low. It is somewhat surprising seeing these topics ignored; therefore, they should be investigated fully to provide improvements in the field. It was seen that in a distance education research, we might use a quantitative, qualitative, or mixed research design as in many other social research fields. As qualitative and quantitative research design has some shortcomings, a more mixed research method may be provided to remove these weaknesses and to fully understand the history and future of MOOCs and open educational resource concepts. Since the distances are not so far away as before, it is seen that distance education technologies may take the role of typical educational systems. Nowadays, this idea is intensely discussed. Thus, maybe in near future, the legality of distance formal education and their standards may be a promising research area. On the other hand, some future research ideas may be based on online learning design and the use of learning analytics to create actionable knowledge that can contribute to pedagogical effectiveness in open and distance education courses. In conclusion, while not all journals could be included in this study, the results from a focused study on topics in specific distance education journals did provide insight for researchers by highlighting common gaps in the field. 


\section{References}

Adams Becker, S., Cummins, M., Davis, A., Freeman, A., Hall Giesinger, C., \& Ananthanarayanan, V. (2017). NMC horizon report: 2017 higher education edition. Austin, Texas: The New Media Consortium. Retrieved from http://cdn.nmc.org/media/2017-nmc-horizon-report-he-EN.pdf

Ariadurai, S. A., \& Manohanthan, R. (2008). Instructional strategies in teaching engineering at a distance: Faculty perspective. The International Review of Research in Open and Distributed Learning, 9(2). 1-11. doi: 10.19173/irrodl.v9i2.461

Atkins, D. E., Brown, J. S., \& Hammond, A. L. (2007). A review of the open educational resources (OER) movement: Achievements, challenges, and new opportunities. The William and Flora Hewlett Foundation. Retrieved from https://hewlett.org/wpcontent/uploads/2016/o8/ReviewoftheOERMovement.pdf

Bates, A. W. (1997). The impact of technological change on open and distance learning. Distance Education, 18(1), 93-109. doi:10.1080/0158791970180108

Bauer, L. (2003). Introducing linguistic morphology. Edinburgh: Edinburgh University Press.

Berge, Z. L., \& Mrozowski, S. (2001). Review of research in distance education, 1990 to 1999. American Journal of Distance Education, 15(3), 5-19. doi: 10.1080/08923640109527090

Bernard, L., Paton, V., \& Lan, W. (2008). Online self-regulatory learning behaviors as a mediator in the relationship between online course perceptions with achievement. The International Review of Research in Open and Distributed Learning, 9(2). 1-11. doi:10.19173/irrodl.v9i2.516

Bishop, M. J., \& Elen, J. (2014). Model-based learning and performance. In J. M. Spector, M. D. Merrill, J. Elen, \& M. J. Bishop (Eds.), Handbook of research on educational communications and technology (pp. 673-674). New York, NY: Springer.

Bozkurt, A., Akgun-Ozbek, E., Yilmazel, S., Erdogdu, E., Ucar, H., Guler, E. ... \& Dincer, G. D. (2015). Trends in distance education research: A content analysis of journals 2009-2013. The International Review of Research in Open and Distributed Learning, 16(1). 330-363. doi:10.19173/irrodl.v16i1.1953

Bozkurt, A., Akgün-Özbek, E., \& Zawacki-Richter, O. (2017). Trends and patterns in massive open online courses: Review and content analysis of research on MOOCs (2008-2015). The International Review of Research in Open and Distributed Learning, 18(5). 118-147. doi:10.19173/irrodl.v18i5.3080

Bozkurt, A., Keskin, N. O., \& de Waard, I. (2016). Research trends in massive open online course (MOOC) theses and dissertations: Surfing the tsunami wave. Open Praxis, 8(3), 203-221. doi:10.5944/openpraxis.8.3.287 
Cohen, L., Manion, L., \& Morrison, K. (2007). Research methods in education (6 $6^{\text {th }}$ ed.). New York, NY, US: Routledge/Taylor \& Francis Group.

Cooper, R. (2010). The generalized social body: Distance and technology. Organization, 17(2), 242-256. doi: $10.1177 / 1350508409337583$

Davies, R. S., Howell, S. L., \& Petrie, J. A. (2010). A review of trends in distance education scholarship at research universities in North America, 1998-2007. The International Review of Research in Open and Distributed Learning, 11(3), 42-56. doi: 10.19173/irrodl.v11i3.876

Diver, P., \& Martinez, I. (2015). MOOCs as a massive research laboratory: Opportunities and challenges. Distance Education, 36(1), 5-25. doi:10.1080/01587919.2015.1019968

Giannakos, M. N. (2013). Exploring the video-based learning research: A review of the literature. British Journal of Educational Technology, 44(6), 191-195. doi:10.1111/bjet.12070

Hodder, I. (1994). The interpretation of documents and material culture. Thousand Oaks: Sage.

Johnson, L., Laurence, F., Levine, A., Smith, R., \& Stone, S. (2010). The 2010 horizon report. Austin, Texas: The New Media Consortium. Retrieved from https://www.nmc.org/pdf/2010-HorizonReport.pdf

Keegan, D. (1996). Foundations of distance education ( $3^{\text {rd }}$ ed.). London: Routledge.

Kovanović, V., Joksimović, S., Gašević, D., Siemens, G., \& Hatala, M. (2015). What public media reveals about MOOCs: A systematic analysis of news reports. British Journal of Educational Technology, 46(3), 510-527. doi:10.1111/bjet.12277

Kukulska-Hulme, A. (2007). Mobile usability in educational contexts: What have we learnt? The International Review of Research in Open and Distributed Learning, 8(2). 1-16. doi:10.19173/irrodl.v8i2.356

Lee, K. (2017). Rethinking the accessibility of online higher education: A historical review. The Internet and Higher Education, 33, 15-23. doi:10.1016/j.iheduc.2017.01.001

Lowenthal, P., \& Wilson, B. G. (2010). Labels do matter! A critique of AECT's redefinition of the field. TechTrends, 54(1), 38-46. doi:10.1007/s11528-009-0362-y

Luschei, T. F., Dimyati, S., \& Padmo, D. (2008). Maintaining e3-learning while transitioning to online instruction: The case of the Open University of Indonesia. Distance Education, 29(2), 165-174. doi: 10.1080/01587910802154962 
Martin, F., Ahlgrim-Delzell, L., \& Budhrani, K. (2017). Systematic review of two decades (1995 to 2014) of research on synchronous online learning. American Journal of Distance Education, 31(1), 3-19. doi:10.1080/08923647.2017.1264807

Moore, J. L., Dickson-Deane, C., \& Galyen, K. (2011). E-learning, online learning, and distance learning environments: Are they the same? The Internet and Higher Education, 14(2), 129-135. doi:10.1016/j.iheduc.2010.10.001

Morgan, J. (2006). Learner and teacher electronic relations: Experiences of one distance learning health studies programme. European Journal of Open, Distance and E-learning, 9(1). 1-7. Retrieved from http://www.eurodl.org/?p=archives\&year $=2006 \& \&$ article $=218$

Nasiri, F., \& Mafakheri, F. (2015). Postgraduate research supervision at a distance: A review of challenges and strategies. Studies in Higher Education, 4O(10), 1962-1969.

doi:10.1080/03075079.2014.914906

Oliver, R. L. (2014). Satisfaction: A behavioral perspective on the consumer. New York, NY: Routledge.

Petticrew, M., \& Roberts, H. (2008). Systematic reviews in the social sciences: A practical guide. New Jersey, USA: John Wiley \& Sons.

Russell, G. (2006). Online and virtual schooling in Europe. European Journal of Open, Distance and Elearning, 9(1). 1-7. Retrieved from http://www.eurodl.org/materials/contrib/2006/Glenn Russell.pdf

Sherry, L. (1996). Issues in distance learning. International Journal of Educational Telecommunications, 1(4), 337-365. Retrieved from https://www.learntechlib.org/primary/p/8937/

Shih, M., Feng, J., \& Tsai, C. C. (2008). Research and trends in the field of e-learning from 2001 to 2005: A content analysis of cognitive studies in selected journals. Computers \& Education, 51(2), 955967. doi:10.1016/j.compedu.2007.10.004

Simonson, M., Smaldino, S. A., Albright, M. M., \& Zvacek, S. (2011). Teaching and learning at a distance: Foundations of distance education. Boston: Pearson Education.

Simonson, M., Smaldino, S., \& Zvacek, S. (2015). Teaching and learning at a distance: Foundations of distance education (6th ed.). Charlotte, NC: Information Age.

Tucker, B. (2012). The flipped classroom. Education Next, 12(1), 82-83. Retrieved from http://www.msuedtechsandbox.com/MAETELy22015/wpcontent/uploads/2015/07/the flipped classroom article 2.pdf 
Veletsianos, G. (2010). A definition of emerging technologies for education. In G. Veletsianos (Ed.), Emerging technologies in distance education (pp. 3-22). Edmonton, AB: Athabasca University Press.

Zawacki-Richter, O., Alturki, U., \& Aldraiweesh, A. (2017). Review and content analysis of the international review of research in open and distance/distributed learning (2000-2015). The International Review of Research in Open and Distributed Learning, 18(2), 1-26. doi:10.19173/irrodl.v18i2.2806

Zawacki-Richter, O., Bäcker, E., \& Vogt, S. (2009). Review of distance education research (2000 to 2008): Analysis of research areas, methods, and authorship patterns. The International Review of Research in Open and Distributed Learning, 10(6), 21-50. doi:10.19173/irrodl.v10i6.741

Zawacki-Richter, O., \& Naidu, S. (2016). Mapping research trends from 35 years of publications in Distance Education. Distance Education, 37(3), 245-269. doi:10.1080/01587919.2016.1185079 